
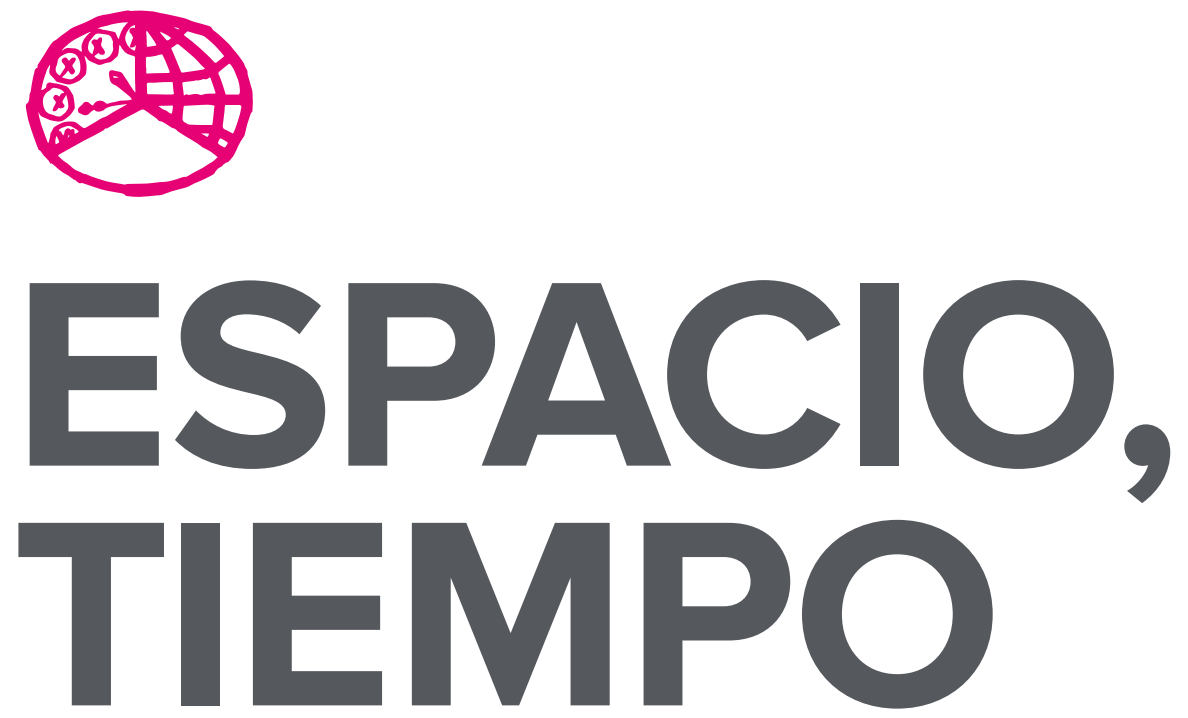

AÑO 2017

ISSN 1131-7698

E-ISSN 2340-1354
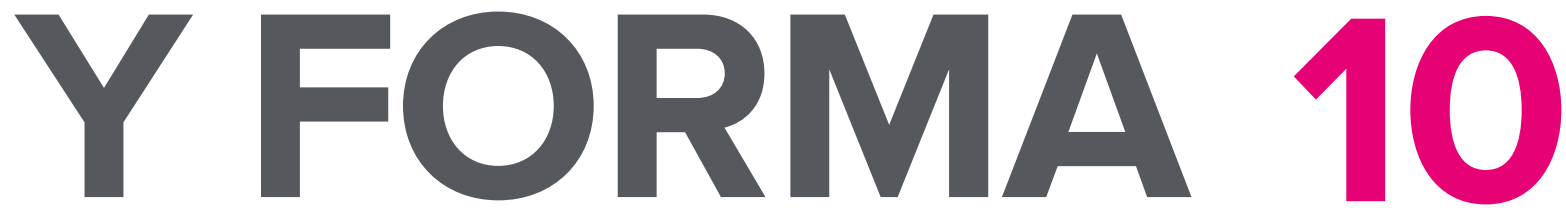

SERIE I PREHISTORIA Y ARQUEOLOGÍA

REVISTA DE LA FACULTAD DE GEOGRAFÍA E HISTORIA 


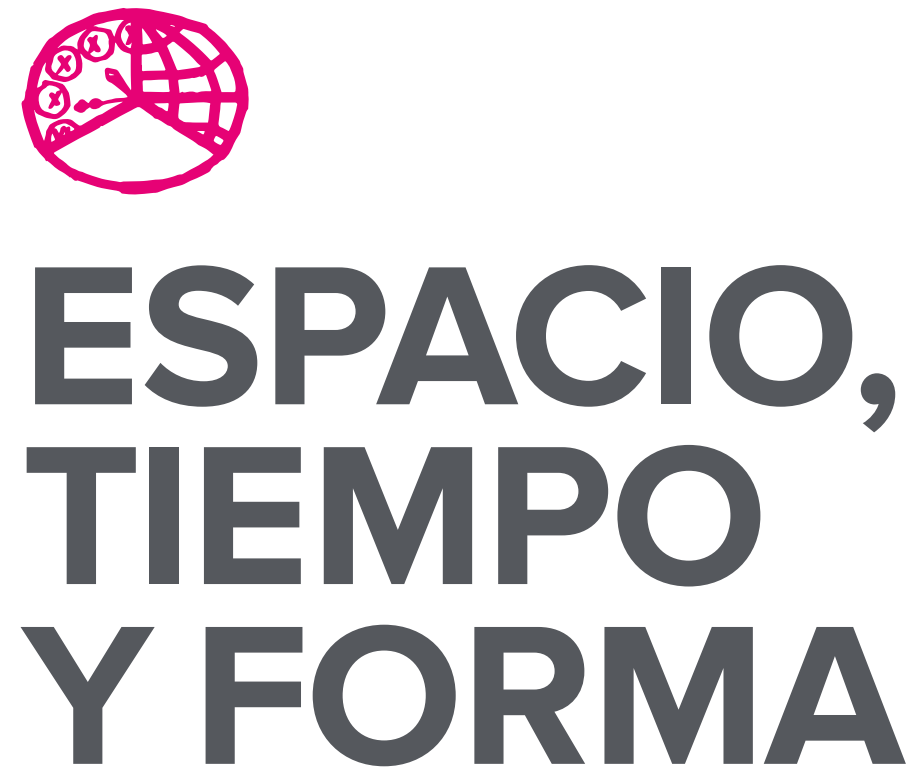

AÑO 2017

ISSN 1131-7698

E-ISSN 2340-1354

SERIE I PREHISTORIA Y ARQUEOLOGÍA

REVISTA DE LA FACULTAD DE GEOGRAFÍA E HISTORIA

DOI: http://dx.doi.org/10.5944/etfi.10.2017

\section{UกED}

UNIVERSIDAD NACIONAL DE EDUCACIÓN A DISTANCIA 
La revista Espacio, Tiempo y Forma (siglas recomendadas: ETF), de la Facultad de Geografía e Historia de la UNED, que inició su publicación el año 1988, está organizada de la siguiente forma:

$$
\begin{aligned}
& \text { SERIE I - Prehistoria y Arqueología } \\
& \text { SERIE II - Historia Antigua } \\
& \text { SERIE III - Historia Medieval } \\
& \text { SERIE IV - Historia Moderna } \\
& \text { SERIE V - Historia Contemporánea } \\
& \text { SERIE VI - Geografía } \\
& \text { SERIE VII - Historia del Arte }
\end{aligned}
$$

Excepcionalmente, algunos volúmenes del año 1988 atienden a la siguiente numeración:

$$
\begin{aligned}
& \mathrm{N}^{\circ} 1 \text { - Historia Contemporánea } \\
& \mathrm{N}^{\circ} 2 \text { - Historia del Arte } \\
& \mathrm{N}^{\circ} 3 \text { - Geografía } \\
& \mathrm{N} .^{\circ} 4 \text { - Historia Moderna }
\end{aligned}
$$

ETF no se solidariza necesariamente con las opiniones expresadas por los autores.

\author{
UNIVERSIDAD NACIONAL DE EDUCACIÓN A DISTANCIA \\ Madrid, 2017 \\ SERIE I PREHISTORIA Y ARQUEOLOGÍA N..$^{\circ}$ 10, 2017 \\ ISSN 1131-7698 · E-ISSN 2340-1354 \\ DEPÓSITO LEGAL \\ M-21.037-1988 \\ URL \\ ETF I PREHISTORIA Y ARQUEOLOGÍA · http://revistas.uned.es/index.php/ETFI/index \\ COMPOSICIÓN \\ Carmen Chincoa Gallardo \\ http://www.laurisilva.net/cch \\ Impreso en España · Printed in Spain
}

(c) (1) (8) Esta obra está bajo una licencia Creative Commons

Reconocimiento-NoComercial 4.0 Internacional. 


\section{ARTÍCULOS}





\title{
ARQUEOGRAFİA DEL SITIO \\ ARQUEOLÓGICO VISTA AL CERRO \\ (A-516 VC) (LA FORTUNA DE SAN CARLOS \\ CENTRO-NORTE DE COSTA RICA), \\ ESBOZOS DE UN CONTEXTO FUNERARIO \\ EN LA FASE ARENAL (500 A.C-500 D. C)
}

\author{
ARCHEOGRAPHIA OF THE ARCHAEOLOGICAL \\ SITE VISTA DEL CERRO (A- 516 VC) (LA FORTUNA \\ DE SAN CARLOS NORTH CENTRAL COSTA \\ RICA), SKETCHES OF A FUNERARY CONTEXT \\ IN THE ARENAL PHASE (500 BC -500 D. C)
}

Manuel Alejandro Castillo Poveda ${ }^{1}$

Recibido: 16/04/2017 · Aceptado: 06/11/2017

DOI: http://dx.doi.org/10.5944/etfi.10.2017.18809

\section{Resumen}

El presente artículo plantea como objetivo la caracterización del sitio arqueológico Vista del Cerro (A-516VC), con base en los resultados obtenidos de diversas excavaciones como análisis de evidencia precolombina, se presentara un acercamiento al entendimiento de las poblaciones precolombinas que ocuparon dicha zona, como de sus expresiones funerarias de la región Centro-Norte de Costa Rica en 500 a.C-500 d. C.

Palabras clave

Arqueología; Teoría del paisaje; Fase Arenal; San Carlos; Vista del Cerro; Costa Rica.

\section{Abstract}

This article presents as objective the characterization of the archeological site Vista del Cerro (A-5I6VC), based on the results obtained from different excavations as an analysis of pre-Columbian evidence, it presents an approach to the understanding of the pre-Columbian populations that occupied the zone, as well as the funerary expressions of the Central-North region of Costa Rica in 500 BC-500 AD. C.

1. Antropólogo y arqueólogo independiente, graduado de la universidad de Costa Rica; <castillopoveda@gmail.com>. 


\section{Keywords}

Archeology; landscape theory; Arenal Phase; San Carlos; Vista del Cerro; Costa Rica.

\section{INTRODUCCIÓN}

Este artículo toma como base el proceso de evaluación arqueológica efectuada en el sitio ${ }^{2}$ arqueológico Vista del Cerro (A-516 VC), en el cual se observaron 2 alineamientos de cantos ${ }^{3}$ en el corte de una carretera (Badilla, 20I4. Pág. 6); por tal situación el Museo Nacional de Costa Rica, en concordancia con la Ley № 6703 Sobre Patrimonio Nacional Arqueológico, ordeno la intervención de dicho contexto.

Como resultado de las distintas excavaciones y análisis de la evidencia obtenida en la evaluación arqueológica (Castillo, 2015), se logró caracterizar este sitio arqueológico, el cual denominado como Vista del cerro (A-5I6 VC), la misma abarco apartados referentes a su temporalidad, contexto, función, dinámica efectuada y paisaje con el que se relaciona.

Por esta razón se llevara a cabo la exposición de la evidencia arqueológica hallada, en la cual resaltan artefactos cerámicos, líticos, conformaciones de cantos con relación a espacios vacíos, huellas de quemado, señales de intercambio con otras áreas pobladas en ese entonces y una disconformidad temporal a esquemas propuestos para el área.

Con relación a su paisaje y al carácter de la manifestación cultural señalada para el sitio, se realizarán inferencias sobre la dinámica llevada a cabo en el mismo, de manera que se generará un panorama general sobre las actividades en Vista del Cerro, que las evidencias arqueológicas en él halladas permiten interpretar como prácticas culturales.

Además de hacer constar una gráfica del sitio arqueológico Vista del Cerro, este trabajo busca enriquecer dicha temática explorada en la región por parte de otros investigadores (Sheets, 2008; Butler. 2003; Guerrero, et al., 2003), con el fin de poder contribuir al entendimiento referido a las practica funeraria o de enterramiento dentro de las poblaciones antiguas del área centro-norte de Costa Rica.

2. «lugares relacionados que han sido gradualmente revelados mediante las interacciones y actividades habituales con las personas, a través de la proximidad y la afinidad que éstas han desarrollado con ciertos emplazamientos y a través de acontecimientos importantes» (THOMAS, 2002, p.173).

3. Son rocas pulidas, transportadas por procesos naturales, como las corrientes de agua, los corrimientos de tierra, etc. Fenómenos físicos que provocan en la roca la adquisición de una forma redondeada u oblonga, sin aristas y con la superficie lisa, debido al desgaste sufrido por los procesos erosivos durante el transporte, generalmente causados por la corrosión o las corrientes de agua. 


\section{CONTEXTUALIZACIÓN}

El sitio arqueológico Vista del Cerro se encuentra localizado en la provincia de Alajuela, en el cantón de San Carlos y el distrito de La Fortuna (centro-norte de Costa Rica), coordenadas CRTM05 431595,483962547 Este y II58677,4603237I Norte, específicamente en el sector Norte del Rio Burío, dicho terreno es denominado Finca 2 dentro del proyecto «Comunidad campestre La Fortuna», el mismo posee un área estimada de $23.700 \mathrm{~m}^{2}$.

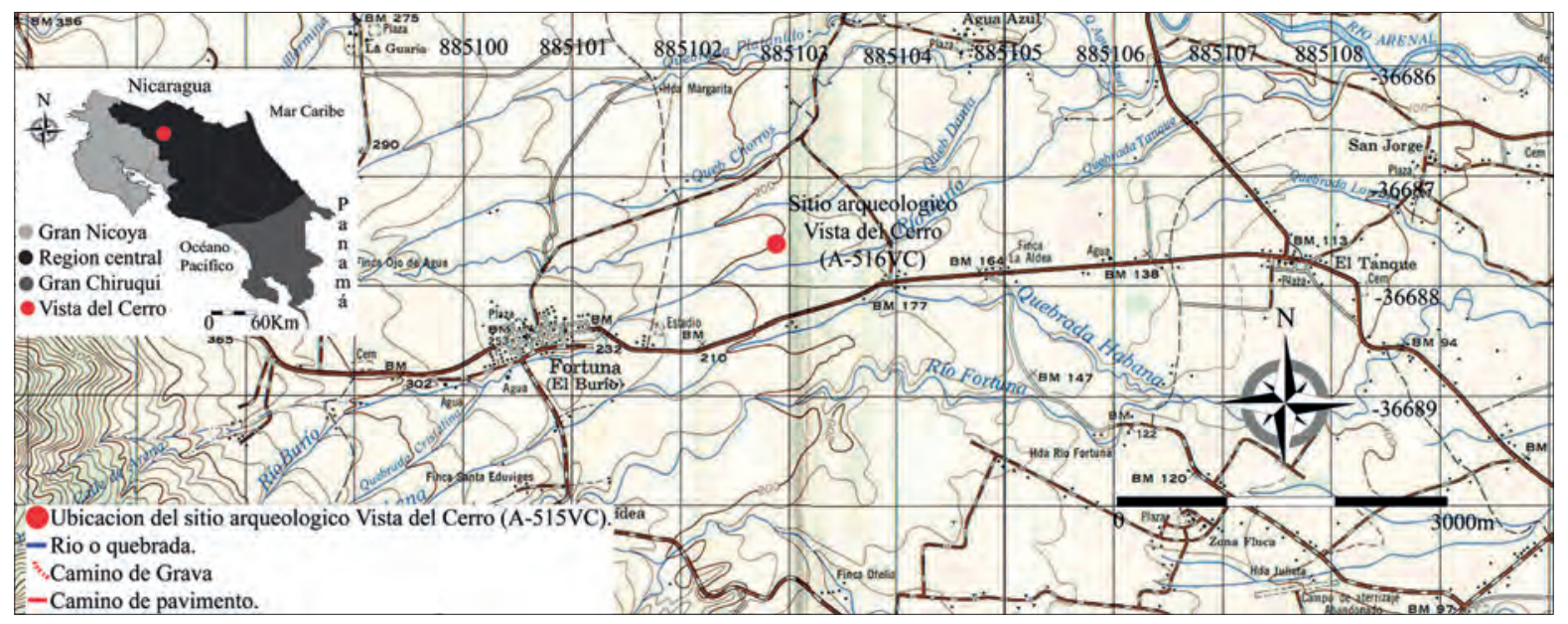

FIGURA 1: LOCALIZACIÓN DEL SITIO ARQUEOLÓGICO VISTA DEL CERRO (A-516CV). CON BASE EN LA HOJA CARTOGRÁFICA LA FORTUNA (3247 II) DEL INSTITUTO GEOGRÁFICO DE COSTA RICA.

La topografía del área donde se encuentra el sitio arqueológico Vista del Cerro es relativamente homogénea, con pocas irregularidades, las cuales son producto del desarrollo habitacional en la zona, además, cabe recalcar la presencia de una calle pública que atraviesa la finca 2 de Norte a Sur, la cual se halla a I,40m bajo el nivel perteneciente a los lotes.

Otros elementos que caracterizan al entorno responden a empedrados modernos pertenecientes a la industria ganadera, fuentes de agua cercanas (rio Burío y quebrada Danta), una variada vegetación (esta verificada en las áreas donde no han iniciado el proceso de urbanización) y una panorámica del volcán Arenal.

Afín al registro arqueológico, existen numerosos sitios registrados ${ }^{4}$ en las cercanías a Vista del Cerro, relación que no solo abarca términos espaciales, si no

4. En este artículo se tomó en cuanta los trabajos de registro de sitios arqueológicos cercanos a Vista del Cerro (A-516VC), las cuales remiten a: La Fortuna (La Habana) (A-43 LF), Doris StONE, Vicente Guerrero y Federico Solano (1962); El Tajo (A-375 ET), Cuñuñunga (A-376 Cñ) y El Castillo (A-377 EC) (Carlos AguILAR, (1977); Los Cedeños (A-178LC), Anochecer (A-179 An) El Primo (A-18oEP), Platanillo-1 (A-181Pt-1) y Platanillo-2 (A-182Pt-2) Marilynn Mueller, (1979); Agua Azul (A-184AA) y Vaca Negra (A-187VN) Marilynn Mueller (1985); Cheppe-1 (A-50 chp-1), Guayabon (A-52 Gb), Cesar (A-51 Cs) y Cheppe-2 (A-55 Chp-2), Timboril (A-54 TI), Pinal (A-56 Pa), El Jardín (A-57 EJ), Tanque Mirador (A-59 TM Monterrey (A-61 Mo La Guaria (A-62 LG), Alamo (A-63 Al), Lomas (A-64 Lo) y Quebrada Azul (A-67 QA ), Agua Azul (A- 70 AA) Marilynn Mueller (1989); San Francisco (A-65 SF) Daniel RojAS, (1989); Jauúri (A-28ju) y Allan (A-99Al). Familia Varela (A-29 FV) Juan Vicente Guerrero (1993); Finca Solís (A-75 FS) Guillermo INDUNI (1996); Cerro Chato (A-167 CCh) Anayensy HerRerA (1997) y Quiebragradiente (A-515 AQ) Anayensy HERRERA (2014). 
que comprende parámetros temporales 5 . Con relación al tema, resaltan las labores realizadas por parte del proyecto Prehistórico Arenal (Sheets, I984), cuyos resultados fueron publicados en el año de ig84 en la revista Vínculos.

Este proyecto se enfocó en estudiar el efecto de la actividad volcánica en dicha área (cuenca del Arenal, cordillera de la región de Tilaran), tal publicación expone los datos de distintas excavaciones efectuadas, los sitios arqueológicos registrados (Neblina [G-I5I Ne], Las Piedras [G-I52 LP]) y su clasificación según sus características (funerario, habitacional) (Chenault, I984a; Bradley, I984; Hoopes, I984a).

Además, expone una propuesta referente a la secuencia cerámica del área, la cual abarca una cronología (esta se divide en las fases [Tronadora (I500-500 a.C], Silencio [800-I350 d.C] y Tilaran [Iooo-I50o d.C]), y la asociación a ciertos tipos cerámicos, como la descripción estilística de dicha evidencia (Hoopes, I984b).

Respecto a la evidencia de carácter lítico, se lleva a cabo la descripción y y el estudio de funcionalidad, además de su correspondiente a la industria tallada, pulida, como piqueteada; cabe destacar que también se lleva a cabo un registro y análisis de muestras orgánicas (Sheets, I984b; Chenault, I984b, Matthews, I984, Chenault y Mueller, 1984).

Otro estudio de la zona se data en I985, cuando el arqueólogo John Hoopes lleva a cabo la descripción de la cerámica perteneciente al complejo Tronadora, donde ahonda en el material cerámico obtenido, las formas registradas, la similitud con el material de la fase La Montaña (Iooo a. C. - 300 a. C.), su temporalidad (765 a.C - 560 d.C), además de asociar sus características estéticas y estratigráficas (Hoopes, I985).

Afín al tema, en el año de i994 son publicados por la Universidad de Texas, los resultados del proyecto dirigido por Payson Sheets y Brian Mckee denominado Archaeology, Volcanism, and remote sensing in the Arenal región Costa Rica; en donde abarcan diversos temas, entre ellos una retrospección del proyecto prehistórico Arenal, así como la influencia de la erupción de I968 del volcán Arenal en la estratigrafía del área circundante (Sheets, I994a; Melson, 1994).

Asimismo, se infirió en factores que contribuyen en la zona de estudio para el establecimiento y el vivir de las poblaciones antiguas (Mueller, 1994), a partir de los resultados de excavaciones en distintos sitios que abarco el proyecto (Hoopes y Chenault, I994a, I994b; Bradley, I994a, I994b), como la aplicación de la técnica de teledetección y sus lecturas en relación a las poblaciones antiguas (Mckee y Sever, I994 y Mckee, Sever y Sheets, I994a).

Otras temáticas abarcadas, se ligan al registro, catalogación temporal, función, descripción morfológica como estética de la cerámica de la zona (Hoopes, I995), la industria lítica piqueteada (Sheets, I994b), pulida y piqueteada (Chenault, I994c), el análisis artefactual (Mueller y Chenault, I995), el análisis de fitolitos (Piperno, 1995), el análisis polínico (Clary, 1994) y antracológico (Mahaney, Matthews y Vargas, 1994).

5. Se hace referencia a una coherencia entre rangos temporales en que se haya ubicado determinado sitio arqueológico con relación a Vista del Cerro (A-516VC).

6. Vínculos. Vol. 10. Núm. 1-2. 
Tales abordajes permitieron inferir como la ocupación en esta zona data desde el paleo-Indio, por la aparición en registro de una punta Clovis; fase que se denominó como La Fortuna (3000-4000 a.C.) y que se caracteriza por la acumulación de piedra con huellas de quemado, como craqueladas (Sheets, I994b. Pág. 324).

Dentro de dicho lapso temporal, se estima que se establecen villas, de forma rectangular, con una cerámica muy sofisticada en cuanto a su técnica de elaboración, como en la decoración que presentan (Sheets, I994b. Pág. 325).

En la fase Arenal, se insinúan fenómenos de invasión, migración o desplazamiento, además, se registra un aumento de población con respecto a la fase Silencio (6ooıooo a.C). Se evidencian características de asentamiento como la presencia de cementerios cerca de las villas, definidos por medio de la colocación de rocas de rio y restos cerámicos.

Por último, en la fase Tilara [ıоoo-I50o d.C], se distingue la presencia de pequeños caseríos, cuya cerámica es caracterizada por la presencia de pintura. Además, debido a continuas erupciones del volcán Arenal se redujo la población debido a la transformación de la flora y fauna por tales acontecimientos (Sheets, I994b. Pág. 325).

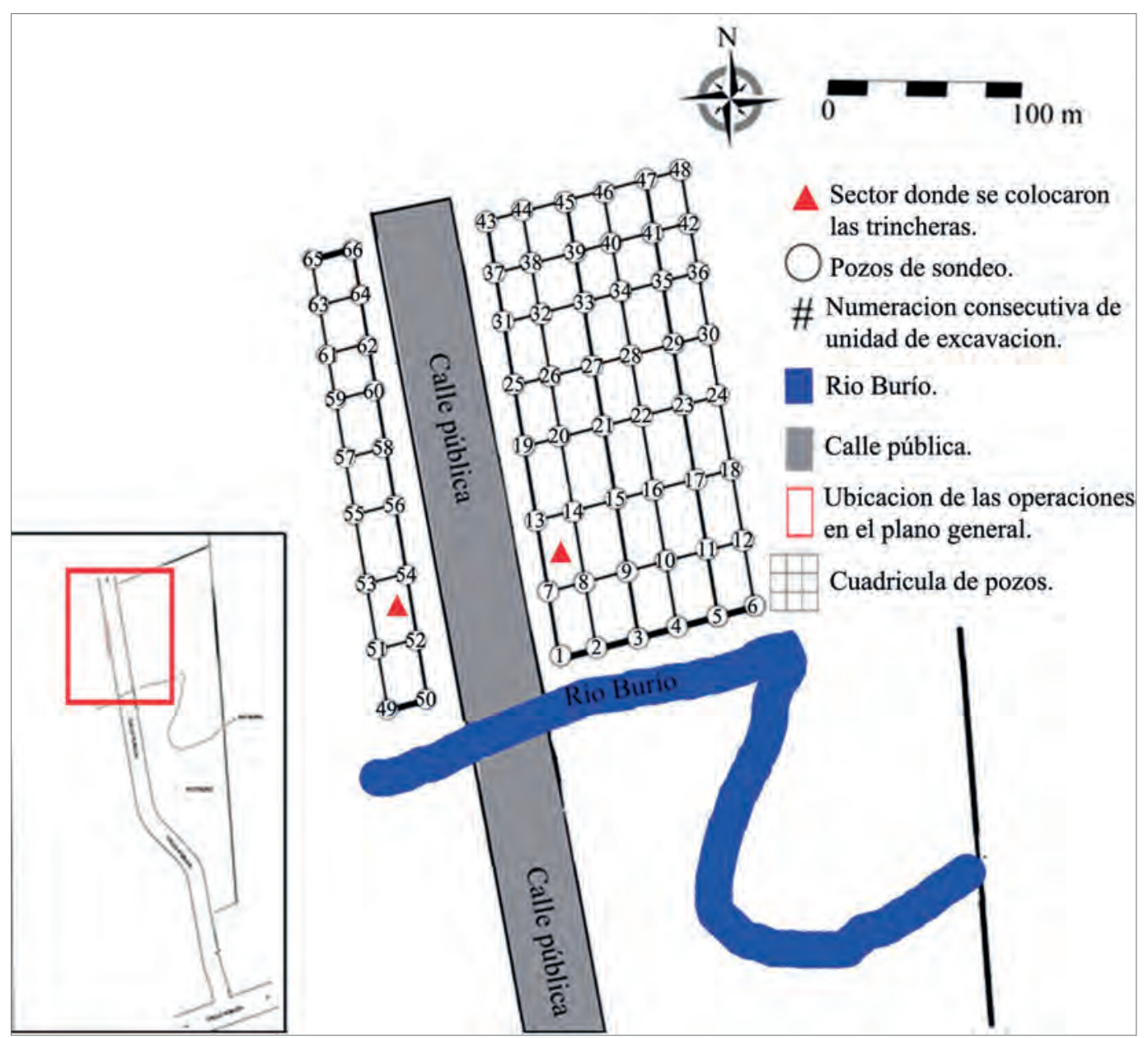

FIGURA 2: DISPERSIÓN DE POZOS DE SONDEO SOBRE EL SECTOR NORTE DE FINCA 2. 
En el 2008, bajo la temática de la memoria social, Payson Sheets infiere la continuidad y fortaleza de las relaciones sociales de los pobladores de esta zona con sus ancestros, a partir de lo hallado en el sitio arqueológico Cañales (G-156). En el mismo, se datan diversas ocupaciones dentro de la fase Tronadora (Iooo- 500 a.C.) (adjudicadas a erupciones volcánicas, tal, afección a la flora y fauna, como él motivo de su desalojo); estas marcadas por la estratigrafía, y la construcción de caminos (mediante el apisonado del suelo), que relacionaban este sitio con otros a una distancia de II $\mathrm{km}$.

\section{PROCESOS ANALÍTICOS}

El trabajo de campo efectuado en el sitio arqueológico Vista del Cerro (A-5I6 VC) consistió en la ejecución de 2 mallas de sondeos (de 48 y I8 unidades), las cuales se extenderían en la totalidad del terreno del sector norte de finca 2. Además se dispuso la colocación de otras excavaciones del mismo tipo (un total de 33) a Io m de donde se hallara material arqueológico, aunado a la colocación de 5 trincheras con el fin de definir extensión, como función del espacio.

Con base en las excavaciones realizadas, se logró definir de los correspondientes alineamientos de cantos, así como el esclarecimiento de su entidad y posible función. Por lo que respecta al análisis del material cultural, la cerámica comprendió dos aspectos, uno funcional, enmarcado en los trabajos de John Hoopes (I984b, I985, I995) y Michael Snarskis (I978) y el otro temporal, basado en los catálogos de John Hoopes (i984b, I985, I995), y Michael Snarskis (I978).

Como resultados de dicha intervención y análisis de la evidencia obtenida, se estimó que el sitio arqueológico Vista del Cerro (A-516 VC), posee un área de $23.700 \mathrm{~m}^{2}$, con una densidad de material cerámico de 0,0003 fragmentos por $\mathrm{m}^{2}$.

Cabe destacar en el sector oeste, la presencia de un espacio empedrado, cuyos componentes líticos difieren en morfología, tono y acabado. Dicha conformación de cantos refiere a un plano (abarca un área de $20 \mathrm{~m}^{2}$ ), con una inclinación de I0 ${ }^{\circ}$ al Este.

El sito es limítrofe con áreas donde la presencia de elementos líticos es ausente, estos refieren a 3 espacios ovoides, un área de forma triangular (con un área de $5 \mathrm{~m}^{2}$ de extensión, cuya composición del suelo que contiene es fino, como tiznado) y 3 circulares (de $60 \mathrm{~cm}$ de diámetro), cuyos cantos perimetrales se hayan colocados de manera vertical con una tonalidad azul-verdosa.

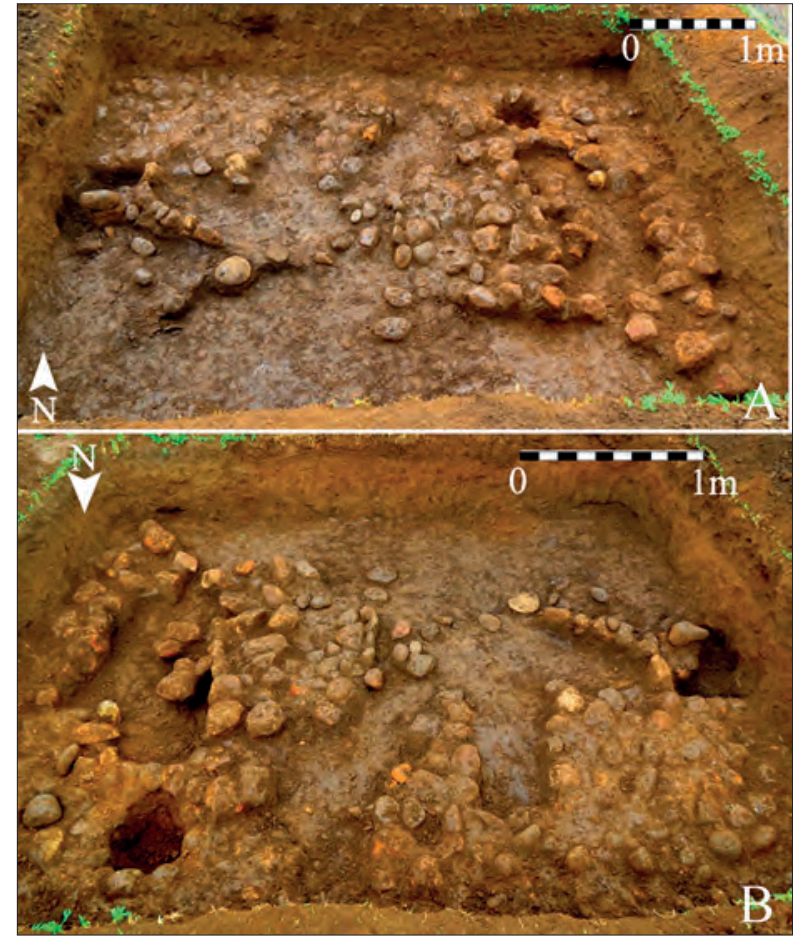

FIGURA 3: FOTOGRAFÍAS DEL EMPEDRADO REGISTRADO, VISTA DESDE EL NORTE AL EMPEDRADO DELA TRINCHERA 5 (A) Y VISTA DESDE EL SUR DE LA MISMA EVIDENCIA (B). 


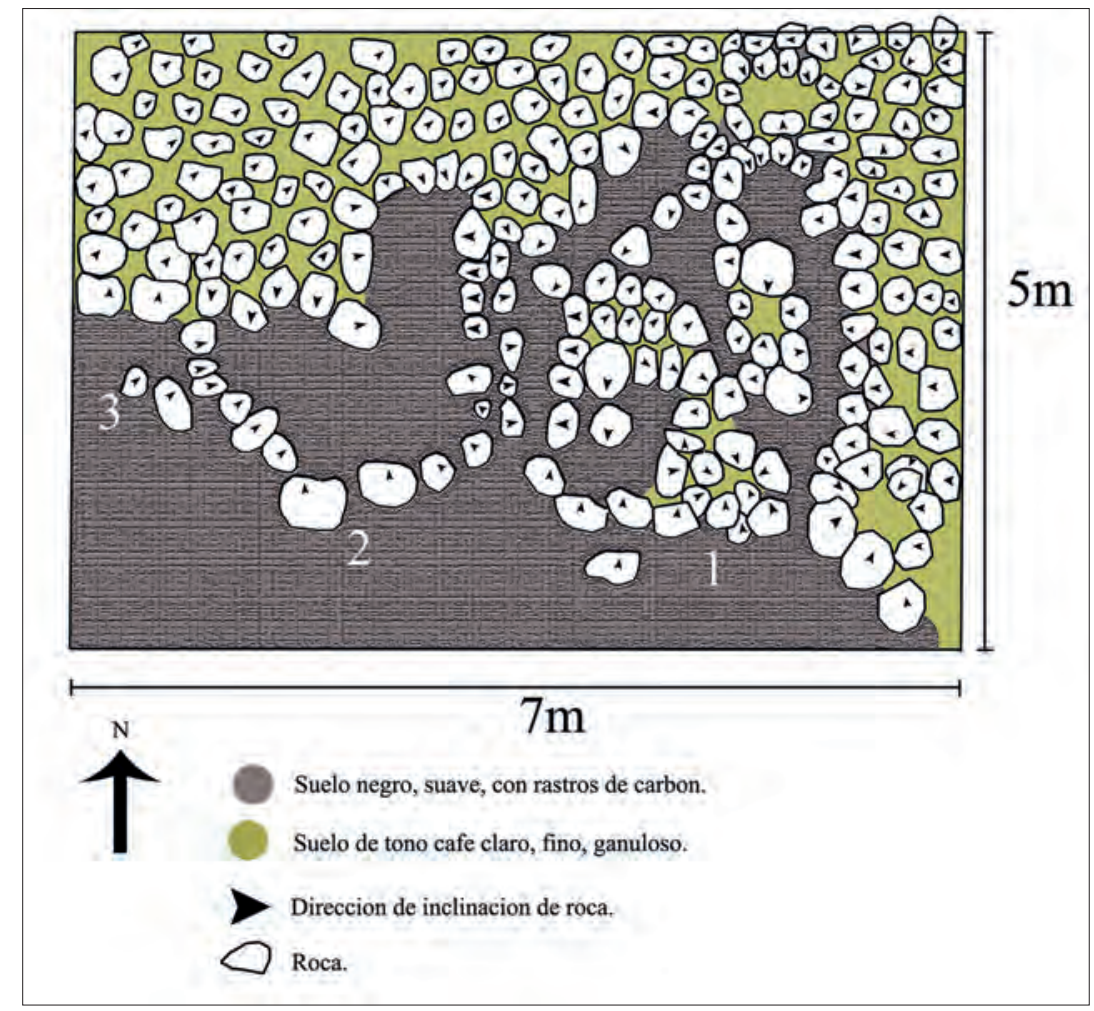

FIGURA 4: PLANIMETRÍA DEL EMPEDRADO REGISTRADO EN EL SECTOR OESTE DE LA FINCA 2.

Con relación a las áreas ovoides, la primera a tratar se halla al Este de la excavación, posee una forma de «C», dimensiones de I,2om de Norte a Sur y $60 \mathrm{~cm}$ de ancho. Al Suroeste, como Noreste de este espacio se halla 2 de las áreas circulares, sin material cultural asociado; al Sur del mismo se encontraron 2 artefactos cerámicos; en relación a su morfología son clasificados como una copa y un jarró, estos colocados de manera boca abajo.
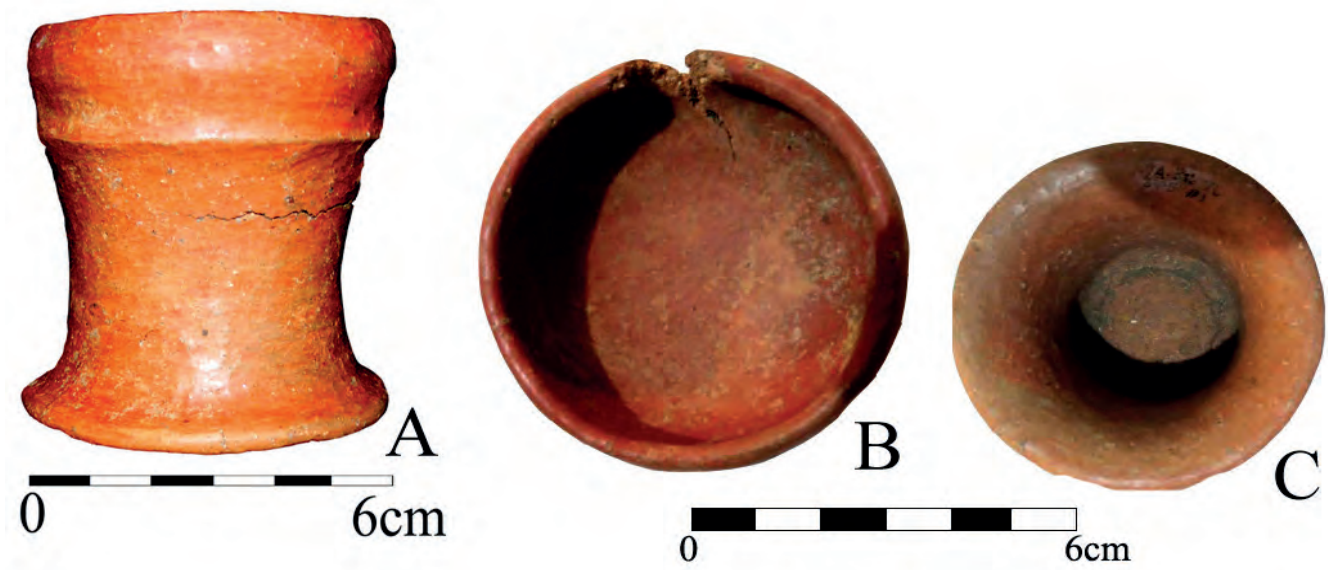

FIGURA 5: ARTEFACTO CON FORMA DE COPA, VISIÓN LATERAL (A), SUPERIOR (B) E INFERIOR (C) DEL ARTEFACTO CON FORMA DE COPA, VÉASE SU UBICACIÓN EN PLANIMETRÍA COMO \#I. 

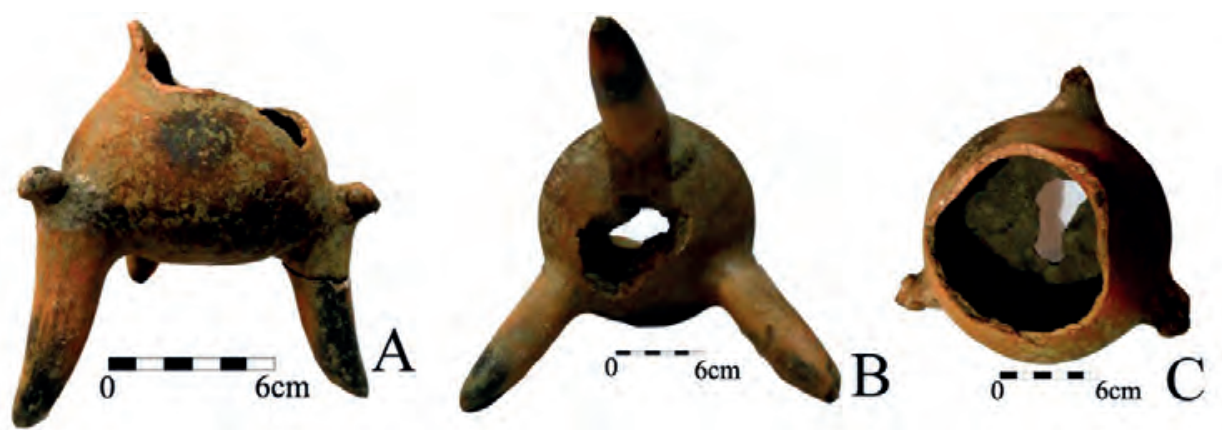

FIGURA 6: ARTEFACTO CON FORMA DE JARRÓN, VISTA LATERAL (A), INFERIOR (B) E SUPERIOR (C), DEL ARTEFACTO CON FORMA DE JARRÓN REGISTRADO EN LA TRINCHERA 1, VÉASE SU UBICACIÓN EN PLANIMETRÍA COMO \#1.

Además, entre el material lítico, se registró la presencia de un fragmento de metate, con un largo de $36 \mathrm{~cm}, 18 \mathrm{~cm}, 3 \mathrm{~cm}$, en el sector oeste del empedrado; demás de 4 artefactos referidos como pulidores ( 2 unidades), un percutor y un núcleo.
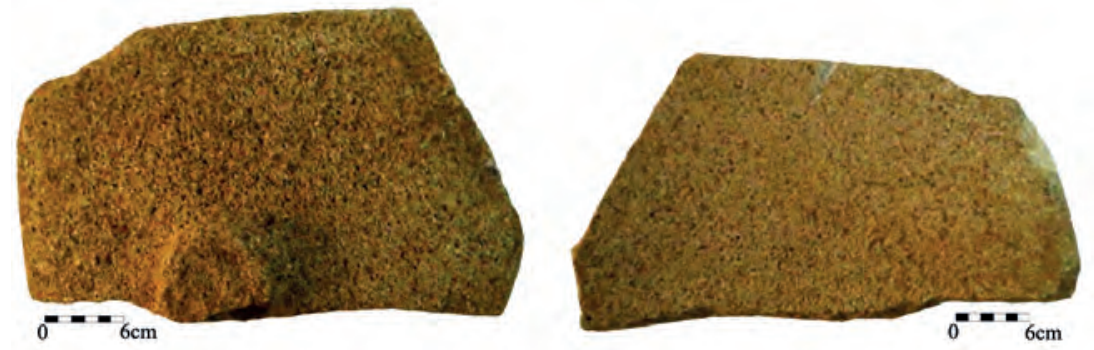

FIGURA 7: FRAGMENTO DE METATE, VISIÓN INFERIOR (IZQUIERDA) Y SUPERIOR (DERECHA) DEL FRAGMENTO DE METATE.
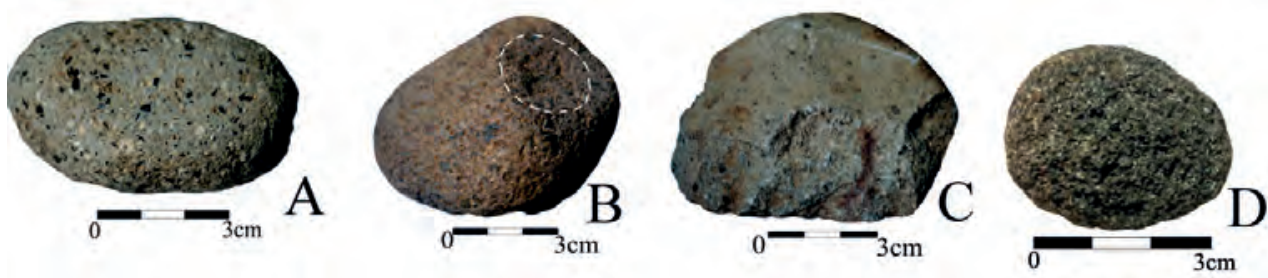

FIGURA 8: MATERIAL LÍTICO CATALOGADO COMO PULIDOR (A Y D), PERCUTOR (B) Y NÚCLEO (C).

A 2,6 $\mathrm{m}$ al Oeste del espacio con forma de «C» se registran otros 3 espacios ovoides con dimensiones semejantes a $\mathrm{I}, 20 \mathrm{~m} \times 60 \mathrm{~cm}$, delimitados por cantos en posición vertical. El primero de estos con una orientación de Noreste a Suroeste, mientras que a I,40m del Oeste.

Los restantes espacios poseen la particularidad de estar unidos por sus ápices sur, evocando una conformación con forma de «V» con una orientación de Noreste a Suroeste, como de Noroeste a Sureste.

Cabe acotar que al Sur de la configuración en «V», se registró un jarrón trípode en posición boca abajo; asociado al mismo, se hallaron 3 soportes semejantes a los del artefacto, que tienen carácter de sonajero (pelota cerámica dentro de soportes 
de vasija, al agitarse o moverse este evoca un sonido por el golpeteo de su cuerpo solido con el interior del soporte).

Dicho jarrón trípode responde al tipo cerámico Impresión Mojica, de la fase Arenal temprano (500 a. C) y tardío (500 d. C), (Hoopes, I995. Pág. I8I-I83). Sin embargo, este no es adjudicado a una variedad específica, debido a la ausencia de la pintura blanca en las descripciones del autor; no obstante, basándose en los soportes de la pieza, remitiría al tipo Inciso Bocana, soportes Bicromo (Hoopes, I995. Pág. I78), el cual se adhiere a la fase Arenal temprano (500 a. C).
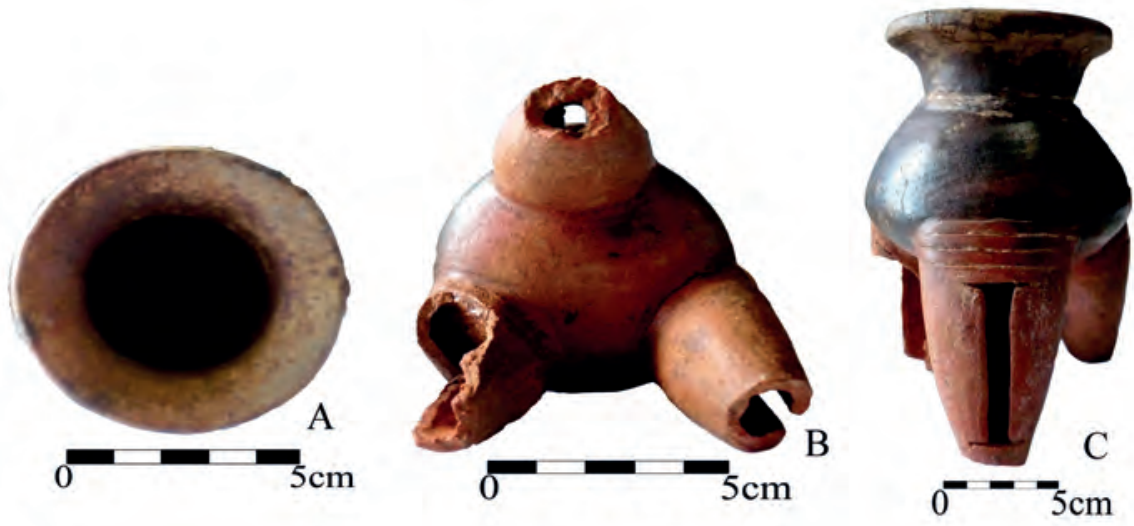

FIGURA 9: ARTEFACTO CON FORMA DE JARRÓN, VISTA SUPERIOR (A), INFERIOR (B), LATERAL (C) DEL ARTEFACTO CON FORMA DE JARRÓN REGISTRADO EN LA TRINCHERA 5, VÉASE SU UBICACIÓN EN PLANIMETRÍA COMO \#2.
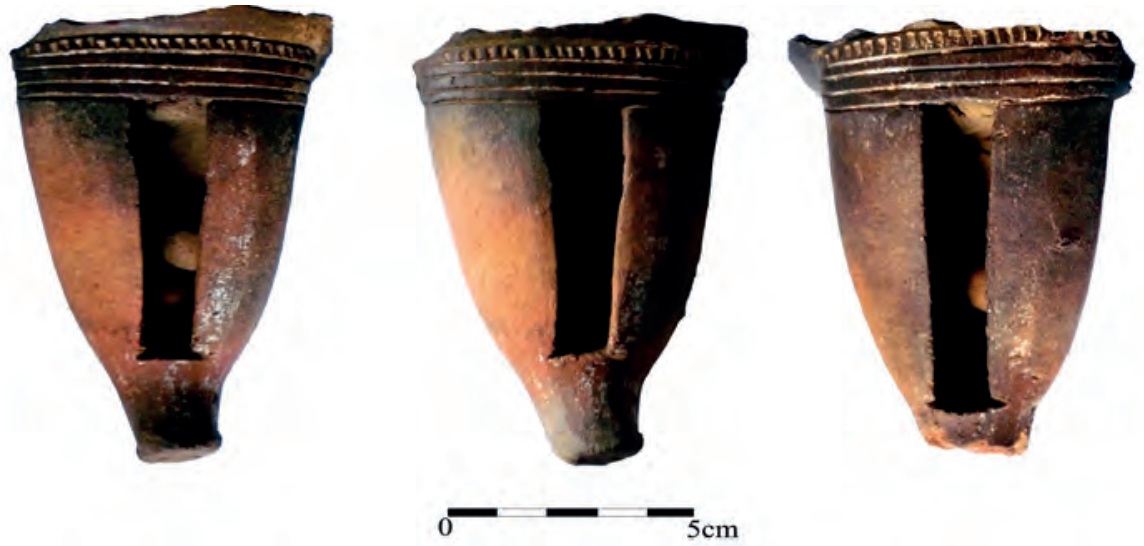

FIGURA 1O: CONJUNTO DE SOPORTES ASOCIADOS AL JARRÓN.

Concerniente al último espacio sin empedrar, refiere a un área circular de 40 $\mathrm{cm}$ de diámetro, la misma se halla adjunta al ápice noroeste del espacio con forma de «V»; de igual manera que los anteriores, está delimitado por cantos en posición vertical y de diversos tonos.

Al Sur de dicho espacio se halla otro jarrón trípode, colocado boca abajo, el cual presenta fracturada la parte correspondiente al cuello fracturada. Este artefacto es asociado al tipo cerámico Impresión Mojica, variedad Laguna, la cual se halla dentro de la fase Arenal tardío (500 d. C) y temprano (500 a. C) (Hoopes, I995. Pág. I8I). 


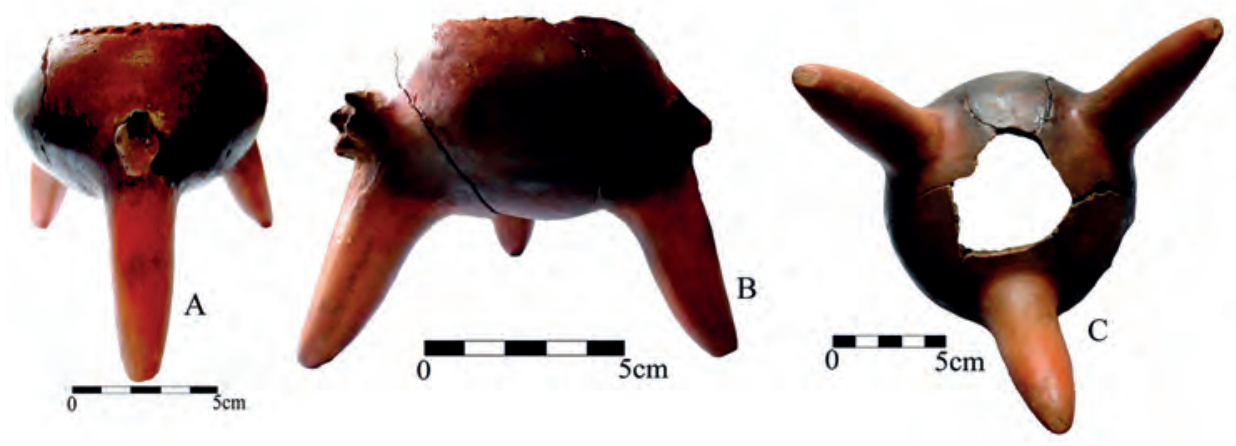

FIGURA 11: ARTEFACTO CERÁMICO CON CUELLO FRACTURADO, VISTA LATERA (A Y B) E INFERIOR (C) DEL ARTEFACTO REGISTRADO EN LA TRINCHERA 5, VÉASE SU UBICACIÓN EN PLANIMETRÍA COMO \#3.

Cabe mencionar que este artefacto presenta en su base una fractura de 5 por $4 \mathrm{~cm}$; en la misma área, en su parte interna, se observa varios trazos táctiles, diferenciándose con su perímetro de carácter liso.

A $23 \mathrm{~m}$ de este empedrado, se halló otra área con las mismas características, en la cual se registró otro espacio circular delimitado por cantos en posición vertical, con un diámetro de $40 \mathrm{~cm}$, al que se le asocian 3 soportes cerámicos correspondientes a una misma vasija. Además, dicha distancia a la cual se dato tal expresión precolombina, definía los límites de la misma.
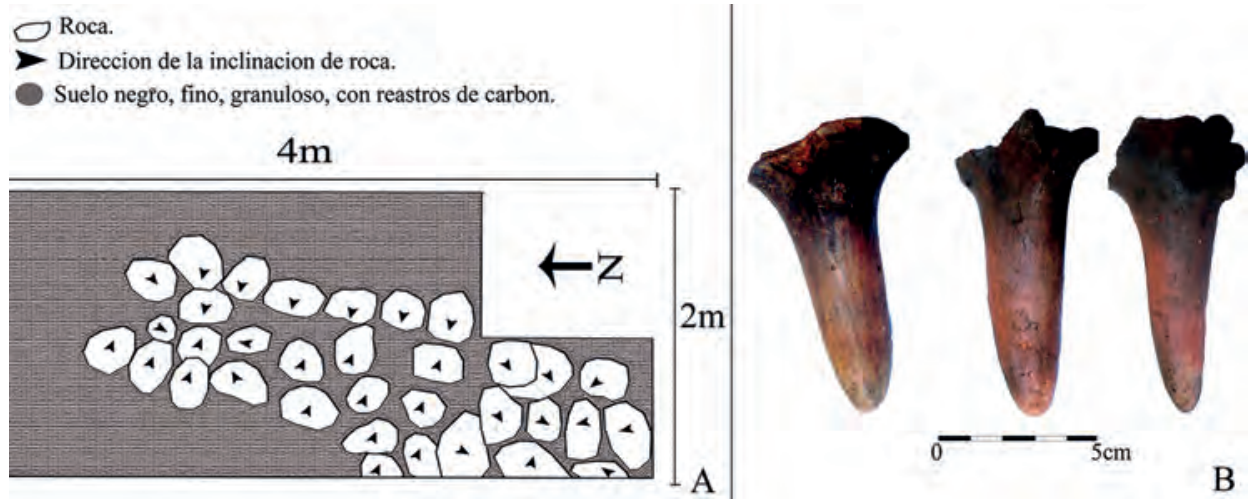

FIGURA 12: PLANIMETRÍA DE ESPACIO CIRCULAR REGISTRADO (A) Y VISTA FRONTAL DE LOS SOPORTES ASOCIADOS A ESPACIO CIRCULAR (B).

Para determinar la asociación temporal de la evidencia arqueológica utilizo la catalogación modal y tipológica referida por John Hoopes (I995), tomando como principal premisa, el eje territorial abarcado en su trabajo titulado Archaeology, Volcanism, and Remote Sensing in the Arenal Región, Costa Rica.

En cuanto a la caracterización del sitio arqueológico Vista del Cerro (516VC), contiene materiales pertenecientes a la fase Arenal (500 a.C-50o d. C) en mayor densidad, así como Tronadora (2000 a. C-500 a. C), remarcando una preponderancia de la evidencia catalogada al lapso tardío sobre el temprano.

Tal aseveración permite el inferir que este espacio fue ocupado esporádicamente en la fase Tronadora (2000 a. C- 500 a. C), concordando con el esquema social 
asignado para este territorio (Sheets, I994b; Sheets, 2008). Posteriormente, se llevó a cabo una sedentarización de la población, en donde se observa la división laboral como espacial, entre estas la funeraria, y más específicamente, de enterramientos diferenciados.

\section{DISCUSIÓN Y CONCLUSIONES}

A partir del estudio de la distribución y densidad de material cerámico como lítico hallado en el sitio arqueológico Vista del Cerro (A-516VC), se estima que este tuvo una ocupación esporádica, como diferenciada, basada en la baja cantidad de material cerámico registrado en relación a las distintas temporalidades en las cuales se catalogan (2000 a.C-500 d. C).

Se infiere que el sitio Vista del Cerro (A-5I6VC) abarca terrenos circundantes al área referida como tal, cabe destacar que se han registrado otros sitios arqueológicos en áreas cercanas a este.

Sin embargo, la evidencia que sustenta su extensión y dimensiones de los mismos no es clara; además de la densidad de material arqueológico correspondiente, por lo que una afiliación funcional es dificultosa.

En relación al registro de sitios arqueológicos proporcionado por el Museo Nacional de Costa Rica, se infiere que este lugar fue parte del conjunto ocupacional de un área mayor, de la cual, se puede distender relaciones con sitios o áreas con registro de presencia de material arqueológico como A-I79AN, A-I8oEP, A-5oCHP-I, A-5ICS, A-52 GB, A-54Tl, A-55 CHP-2, A-56PA, A-57EJ, A-59TM, A-6IMO, A-62LG, A65SF, A-70AA, A-I8IPT-I, A-I82PT-2, A-I83AA, A-I87VN y A-29FV (Io de estos sitios son catalogados dentro de la fase Arenal, i en la fase Tronadora y i en La Selva), cuyo uso se refiere a actividades que difieren de las cotidianas, así como a una frecuencia temporal a corto plazo.

Se discuerda con una larga ocupación o utilización del sitio A-5I6VC, debido al carácter que posee el espacio investigado (enterramientos), estado de los artefactos obtenidos y la baja densidad de evidencias. Aunque se registró material de las distintas etapas de la fase Arenal, esto se interpreta como una fractura en una continuidad rígida de las expresiones estéticas y modales de lo elaborado en el territorio abordado a rangos temporales, los cuales abogan por una diferenciación de estas manifestaciones en distintos grupos o poblados presentes materialmente.

Tal argumento respalda la influencia de otras áreas (Hoopes. I995), basado en el registro de material cuya forma y acabado posee relación con lo expuesto por Snarskis (1978) para la fase La Selva (300-850 d.C.); dicha premisa sustenta la noción de intercambio e intercomunicación entre distintas regiones arqueológicas del territorio costarricense (Guerrero, et al., 2003), sin embargo, a la vez cuestiona la producción de moldes de modos y tipos representativos de una línea temporal como espacial.

Esta proposición disipa la idea de influencia en la construcción de un entorno cultural, además de delimitar manifestaciones culturales a esquemas limítrofes artificiales. 
Retomando la evidencia registrada, remarcando la poca densidad de material arqueológico, aunado al acabado como a la consistencia de su pasta ${ }^{7}$, de la cual, sobresale su grosor, constitución compacta, como desengrasantes de tamaño disminuidos y el registro de un fragmento de metate, el cual posee en uno de sus bordes rastros de tallado. Debido a las características que presenta este último, es descartada su catalogación como de tópico cotidiano.

Conjuntamente, del empedrado explorado, se infiere dimensiones que corresponden a 5 por $23 \mathrm{~m}$, tomando en cuenta la continuidad de la evidencia registrada a lo largo del espacio que es hoy es calle pública. De la cual, resaltan espacios oblongos, delimitados por cantos puestos a manera vertical, dichos lugares se interpretan como tumbas ${ }^{8}$; las cuales presentaban en su extremo sur 4 artefactos cerámicos, 2 de ellos boca abajo y con una perforación semicircular en la base de sus cuerpos.

Esta característica de encontrarse perforada, refiere a un sentido de marca, entendiéndose esta como «formas de expresión articulada del pensamiento humano y, en consecuencia, de la creación práctica» (Bech, 2008: I8), no solo adjudica un carácter intencional, sino que, evoca una especialización para el uso de la misma; dicho enunciado se sustenta en la elaboración de un modelado con los dedos; del cual, se infiere su objetivo, debilitar esta área del artefacto.

Esta práctica remite al paso de los dedos por el interior de la vasija, teniendo el centro del cuerpo como eje, y de ahí hacia los extremos, haciendo que el grosor sea menor que al del resto de las paredes; generando un sector más endeble en la totalidad del cuerpo de la vasija, cuya perforación («matado») puede efectuarse con una mayor posibilidad de no fracturar toda la pieza y dejar la huella de la intención apelada.

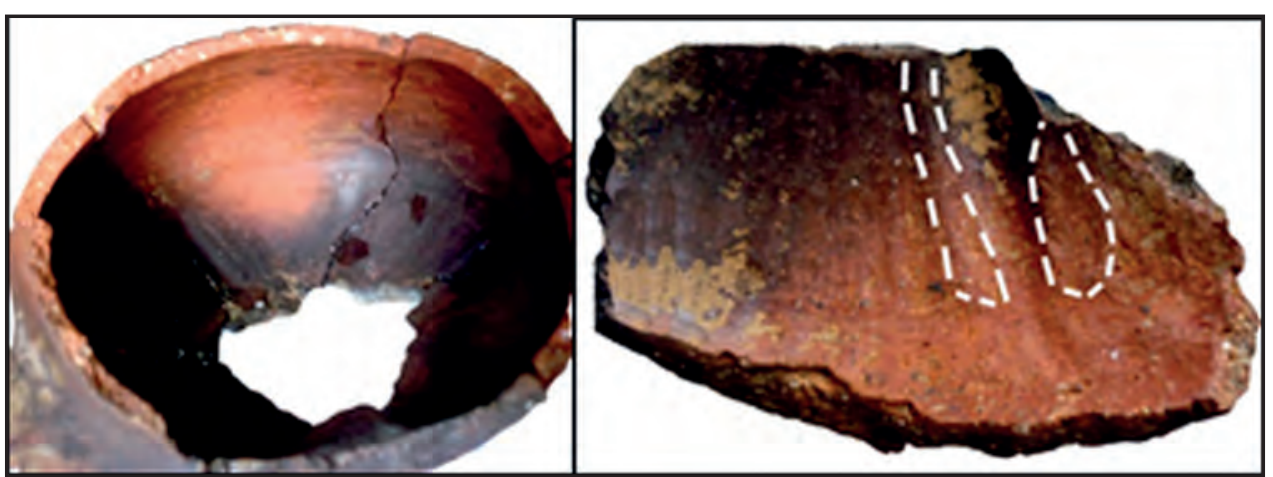

FIGURA 13: FRAGMENTOS DONDE SE OBSERVA EL ADELGAZAMIENTO INTENCIONAL DE LA PARTE INTERNA DE UNA VASIJA.

Además, el mismo empedrado registrado se relaciona a dos conjuntos de tres soportes trípodes que pertenecen a un mismo artefacto; se interpreta que a la hora del matado de la pieza, esta se fractura en mayor grado y la estructura principal se

7. Dicho abordaje utiliza como base los esquemas propuestos por OrTON et al., 1997; CONRAD 1989 y FEINMAN et al., 1981 .

8. Estructura construida para guardar restos mortales (HUNTER y WHITTEN, 1981. Pág. 645). 
fraccionó por completo, cabe retomar la presencia de una capa de carbón ligada al suelo por debajo del empedrado, lo cual induce a pensar en la utilización del fuego.

Cabe hacer mención de la semejanza de los espacios circulares delimitados con cantos, con evidencia registrada en el sitio Poma (G-725 PM), el cual, en los años 2002-2003 Michelle Butler, lo caracteriza como un sitio funerario. En el mismo anota la presencia de círculos de rocas; reportando dentro de ellos la ausencia de artefactos u otro tipo de evidencia, infiriendo el ser espacios de colocación de ofrenda; además, se hace alusión de los tipos cerámicos Hermanos Beige e Impresión Mojica, asociado al rango temporal 500 a.C - 500 d.C, lo cual refiere a ser contemporánea con lo hallado en A-5I6VC.
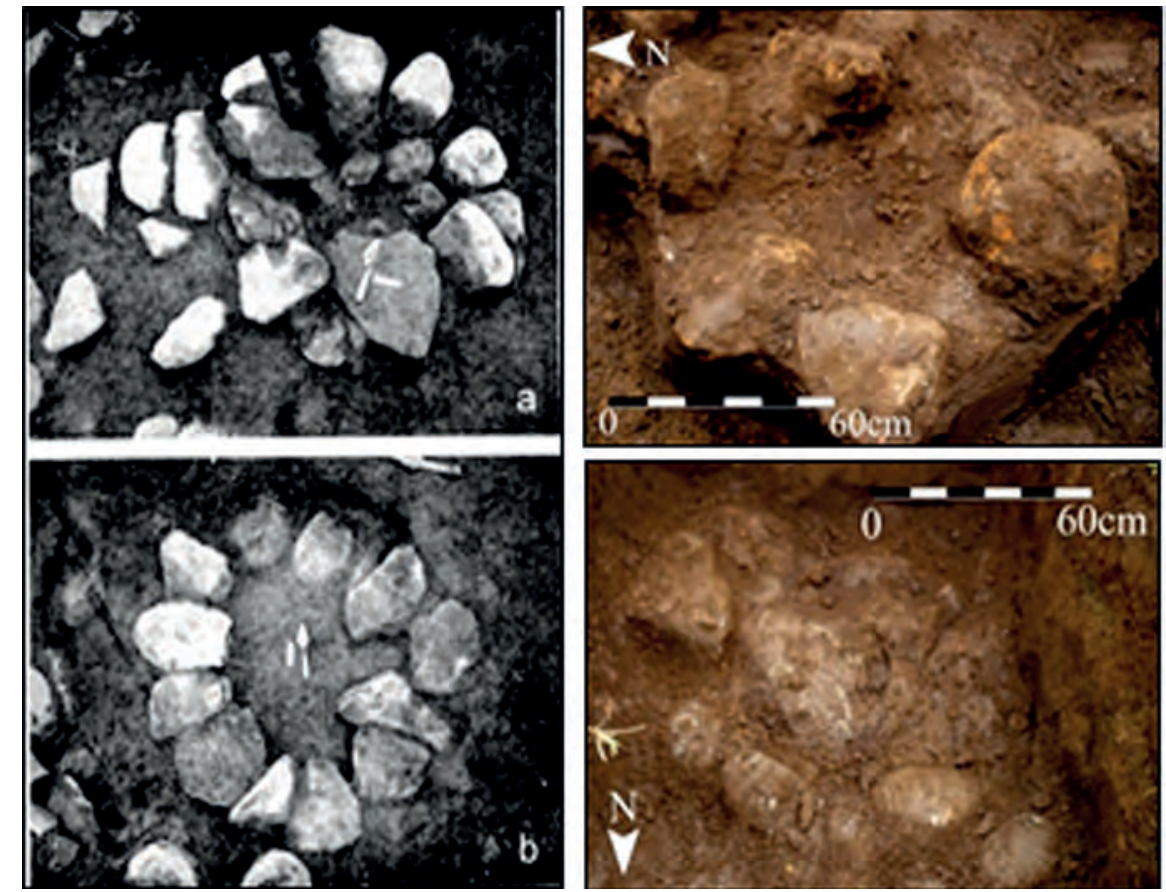

FIGURA 14: CIRCULO DE ROCAS REPORTADO POR BUTLER EN EL 2002-2003 (BUTLER, 2002-2003. PÁG. 65) (IZQUIERDA), CIRCULO DE ROCAS REPORTADO POR CASTILLO 2015 (DERECHA).

Aunado a esto, el sitio arqueológico Vista del Cerro (A-5I6VC), se halla en un área donde la densidad de sitios arqueológicos o concentraciones de material que se encuentran en sus cercanías es alta $\left(36.000 \mathrm{~km}^{2}\right)$, lo cual indica una área extensamente poblada, donde la división espacial permitía una organización de tal territorio, dicho ordenamiento repercutía en el establecimiento de áreas funerarias, ya sea de la población en general o de personajes específicos.

Se infiere que este espacio fue un área funeraria diferenciada, dicho carácter se sustenta a la poca densidad de material cerámico, su concentración en los espacios relacionados al empedrado, la presencia de una estructura construida mediante rocas, como cantos.

Dicha materialidad evoca un gran gasto de energía, a fin de que haya una diferenciación de la actividad mortuoria, así como una selección del material utilizado para su edificación, la colocación de artefactos en lugares específicos, atribuidos de 
cualidades estéticas y artesanales singulares (trípodes, bases adelgazadas), demuestra una devoción en su conjugación con la sociedad de la que formo parte.

Por último, cabe resaltar el papel del paisaje en relación a dicho contexto, ya que el tener una fuente de agua cercana (rio Burío), un suelo fértil, que aún es explotado por dicha cualidad, así como el realce visual del volcán Arenal al Oeste de donde se edificó dichos recintos funerarios, infiere una selección del espacio en sí y una relación en cuanto al significado asignado al mismo, además de contribuir a la diferenciación con otras áreas.
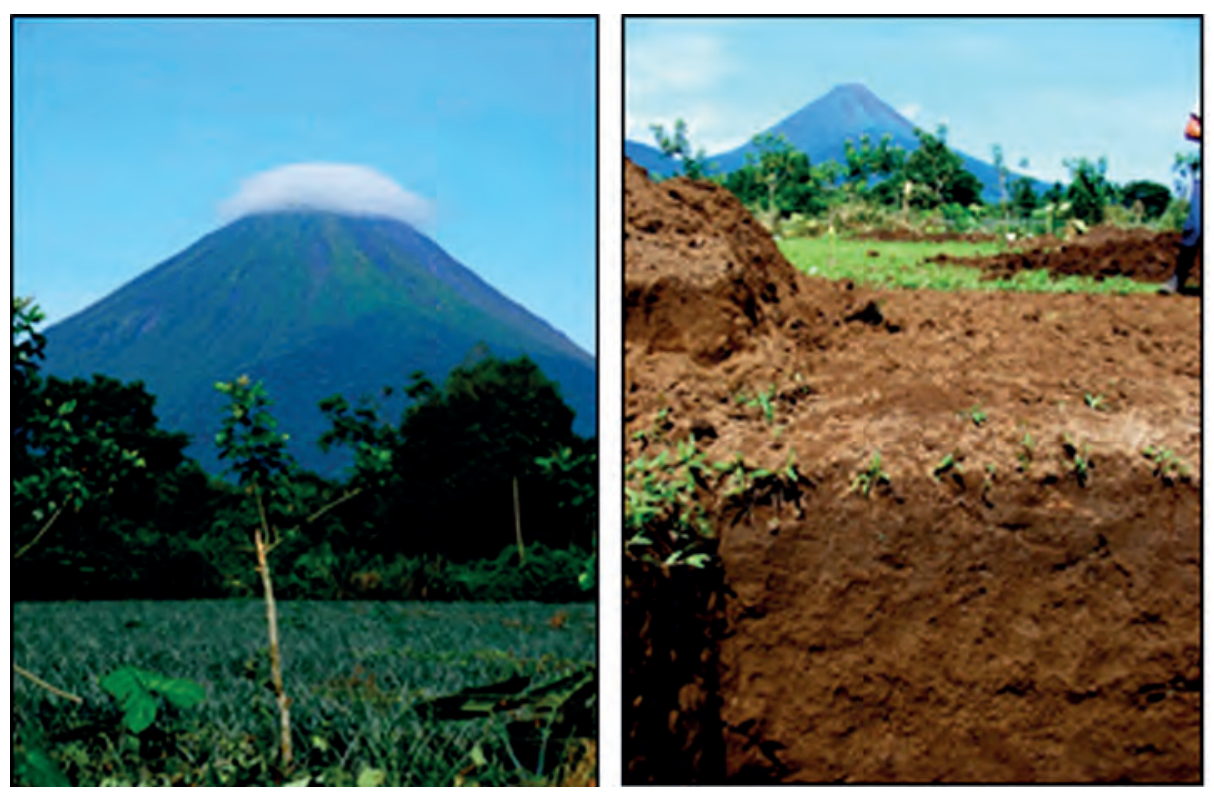

FIGURA 15: VISTA DEL VOLCÁN ARENAL DESDE EL SITIO ARQUEOLÓGICO VISTA DEL CERRO (A-516VC).

El sitio arqueológico Vista del Cerro (A-5I6VC), se muestra como un espacio de ocupación esporádica como recurrente, posee una funcionalidad diferenciada, sustentada en la temporalidad y densidad de la evidencia cerámica, el cual muestra dos rangos temporales, ambos con una presencia material disminuida; otra cualidad a resaltar es su distanciamiento de otros entes de ocupación, evocando una práctica específica en espacio, como en tiempo (Sheets, 2008).

Además, se observa dentro de un empedrado del cual se infiere una extensión de $23 \mathrm{~m}$, se halla la presencia de espacios vacíos, adjudicados como tumbas, en dirección de Oeste-Este, asociadas a lugares circulares igualmente delimitado por cantos, cuya función podría remitir a la colocación de ofrendas al (los) difunto (s) o marcadores.

Se recalca la presencia de un suelo de color oscuro y tiznado que circunda las tumbas y puede responder a una quema o a la utilización del fuego. Además, al Oeste del conjunto de tumbas sobresale del panorama la silueta del volcán Arenal, figura triangular-cónica, cuya denominación es relacionada al «Dios Fuego», a partir de los relatos malekus [Quirós I954, Induni 200o]) con lo que se construye una asociación terminológica con la quema registrada sobre las tumbas y a su alrededor.

Como colorario, el sitio arqueológico Vista del Cerro (A-5I6VC) atañe a un espacio funerario, donde se registró evidencia asociada a la utilización del fuego, 
la colocación de ofrendas y la edificación de espacios ligados a marcadores o depositarios específicos. Además el paisaje donde se localiza es realzado metafóricamente mediante la vista del volcán Arenal (Castillo 2014, 2015a, 2015b; Quiros 1954; Constanza 2010; Gonzales y Gonzales, 2000), por su realce físico, además de cualidades como la emanación de humo y fuego. 


\section{BIBLIOGRAFÍA}

Aguilar, C. I977. Base de datos de Museo Nacional de Costa Rica. Documento inédito.

BADILlA, A. 20I4. Inspección arqueológica proyecto comunidad campestre La Fortuna, La Fortuna de San Carlos, Alajuela. Manuscrito, Museo Nacional de Costa Rica (documento inédito).

$\mathrm{BECH}, \mathrm{A} .2008$. Conceptos básicos para una teoría de la comunicación. Una aproximación desde la antropología simbólica. Revista Mexicana de Ciencias Políticas y Sociales, Vol. L, Núm. 203, Págs. 13-52.

Bradley, J. I984. The proyecto prehistórico Arenal: data control. Vínculos. Vol. io. Núm. -2. Págs. 3I-33.

Bradley, J. I994a. Tronadora Vieja An archaic and early formative site in the Arenal region. En: Sheets, P. y B. McKee (eds.), Archaeology, Volcanism, and Remote Sensing in the Arenal Región, Costa Rica. Págs. 54-73. Austin: University of Texas Press.

BRADLEY, J. I994b. The sinlencio site: an early to middle polychrome period cementery in the Arenal region. En: Sheets, P. y B. Mckee (eds.), Archaeology, Volcanism, and Remote Sensing in the Arenal Región, Costa Rica, Págs. 73-86. Austin: University of Texas Press.

Butler, M. 2003. El sitio Poma, G-725PM, proyecto prehistórico Arenal, 2002-03. Vínculos. Vol. 28. Núm. I-2. Págs. 6I-75.

CAstillo, M. 20I4. Paisaje y arqueología: Arquitectura y conceptualización de las manifestaciones P-oI, P-02, P-03y «encierro» I en el sitio arqueológico Nuevo Corinto ( L-72NC), Caribe Central, Costa Rica. (Tesis inédita de licenciatura). Universidad de Costa Rica, San José.

CAstillo, M. 20I5. Evaluación arqueológica del proyecto de construcción Condominios La Huerta, La Fortuna de San Carlos. Sitio arqueológico Vista al Cerro (A-5I6 VC). Documento inédito.

Chenault, M. I984a. Test excavaction at Neblina and Las Piedras. Vínculos Vol. io. Núm. I-2. Págs. II5-I2O.

Chenault, M. I984b. Ground and polished stone from the Cuenca Arenal. Vínculos io. Núm. I-2. Págs. I67-I85.

Chenault, M. y Mueller, M. i984. Yewllry from the Cuenca Arenal. Vínculos Vol. io. Núm. I-2. Págs. I87-I92.

Chenault, M. I994c. Precolumbian ground, polished, and incised stone artifacs from the cordillera de Tilaran. En: Sheets, P. y B. Mckee (eds.), Archaeology, Volcanism, and Remote Sensing in the Arenal Región, Costa Rica. Págs. 3I-54. Austin: University of Texas Press.

CLARY, K. I994. Pollen evidence for Prehistroic environment and subsistence activiries. En: Sheets, P. y B. Mckee (eds.), Archaeology, Volcanism, and Remote Sensing in the Arenal Región, Costa Rica. Págs. 86-I03. Austin: University of Texas Press.

Conrad, J. 1989. Ceramic formulas: The complete compendium. McMillan Publishing Co, New York.

Constanza, M. 20io. Los volcanes sagrados en el folclore y la arqueología de Costa Rica. Mitológicas. Vol. XXV. Págs. 39-50.

Feinman, G. M., Uphan, S. y Lightfood, K.G. I98I. The Production step measure: an ordinal index of labor input in ceramic manufacture. American Antiquity. Vol. 46. Núm. 4. Págs. 87I-884.

Gonzales A. y Gonzales F. 2000. La casa cósmica Talamanqueña. Costa Rica: Universidad Estatal a distancia. 
Guerrero, J. I993. Base de datos de Museo Nacional de Costa Rica. Documento inédito. Guerrero, J. I994. Base de datos de Museo Nacional de Costa Rica. Documento inédito. Guerrero, J.; Agullar, M. y Peytrequín, P. 2003. La cerámica de dos contextos funerarios de la fase Arenal y Silencio, Región Arenal-Tilaran. Vínculos. Vol. 28. Núm. I-2. Págs. 87-I05. Herrera, A. 1997. Base de datos de Museo Nacional de Costa Rica. Documento inédito. Herrera, A. 20i4. Base de datos de Museo Nacional de Costa Rica. Documento inédito. Hoopes, J. I984a. Prehistoric habitation sites in the Rio Santa Rosa Drainage. Vínculos. Vol. Io. Núm. I-2. Págs. I2I-I28.

Hoopes, J. I984b. A preliminary ceramic sequence for the Cuenca de Arenal, cordillera de Tilaran región, Costa Rica. Vínculos. Vol. Io. Núm. I-2. Págs. I29-I47.

Hoopes, J. I985. Early ceramics and the origins of Village Life in Lower central America. Ph. D. dissertation (Anthropology), Harvard University. Ann: University Microfilms.

Hoopes, J. y Chenault, M. I994a. Proyecto prehistroico Arenal excavations in Santa Rosa river valley. En: SheEts, P. y B. MckeE (eds.), Archaeology, Volcanism, and Remote Sensing in the Arenal Región, Costa Rica. Págs. 7-20. Austin: University of Texas Press.

Hoopes, J. y Chenault, M. I994b. Excavations at sitio Bolivar: a late formative village in Arenal basin. En: Sheets, P. y B. McKee (eds.), Archaeology, Volcanism, and Remote Sensing in the Arenal Región, Costa Rica. Págs. 210-233. Austin: University of Texas Press.

Hoopes, J. I995. Ceramic analysis and culture history in the Arenal region. En: SHEETS, P. y B. MCKeE (eds.), Archaeology, Volcanism, and Remote Sensing in the Arenal Región, Costa Rica. Págs. 233-250. Austin: University of Texas Press.

Hunter, D. y Whitten, P. I981. Enciclopedia de antropología. España: Bellatierra S.A.

Induni, G. 20I4. Base de datos de Museo Nacional de Costa Rica. Documento inédito.

Mckee, B. y Sever, T. 1994. Remote sensing in the Arenal región. En: Sheets, P. y B. Mckee (eds.), Archaeology, Volcanism, and Remote Sensing in the Arenal Región, Costa Rica. Págs. 250-267. Austin: University of Texas Press.

Mckee, B.; Sever, T. Y Sheets, P. 1994. Prehistroic footpaths in Costa Rica: Remote sensing and field verification. En: Sheets, P. y B. Mckee (eds.), Archaeology, Volcanism, and Remote Sensing in the Arenal Región, Costa Rica. Págs. 73-86. Austin: University of Texas Press.

MatTHEws, M. 1984. Results of macrobotanical analysis for the proyecto prehistorico Arenal: preliminary evidence of resourse use and subsistence strategies. Vínculos. Vol. Io. Núm. I-2. Págs. 193-205.

Mahaney, N.; Matthews, M. y VARGaS, A. 1994. Macrobotanical remains of the pryecto prehistorico Arenal. En: SheETs, P. y B. MckeE (eds.), Archaeology, Volcanism, and Remote Sensing in the Arenal Región, Costa Rica. Págs.I70-I92. Austin: University of Texas Press.

Melson, W. 1994. The eruption of 1968 and tephra stratigraphy of Arenal Volcano. En: Sheets, P. y B. Mckee (eds.), Archaeology, Volcanism, and Remote Sensing in the Arenal Región, Costa Rica. Págs. I92-210. Austin: University of Texas Press.

Mueller, M. 1994. Archaeological survey in the Arenal basin. En: Sheets, P. y B. Mckee (eds.), Archaeology, Volcanism, and Remote Sensing in the Arenal Región, Costa Rica. Págs. I44-I70. Austin: University of Texas Press.

Mueller, M. I985. Base de datos de Museo Nacional de Costa Rica. Documento inédito.

Mueller, M. 1989. Base de datos de Museo Nacional de Costa Rica. Documento inédito.

Mueller, M. y Chenault, M. 1994. Prehistoric jewlry from the Arenal basin. En: Sheets, P. y B. Mckee (eds.), Archaeology, Volcanism, and Remote Sensing in the Arenal Región, Costa Rica. Págs. I03-I27. Austin: University of Texas Press. 
PiPerno, D. I995. Phytolith records from the proyecto prehistorico Arenal. En: SHEETs, P. y B. Mckee (eds.), Archaeology, Volcanism, and Remote Sensing in the Arenal Región, Costa Rica. Págs. 127-I44. Austin: University of Texas Press.

Quirós, T. 1954. Geografía de Costa Rica. San José: Ministerio de Obras Costa Rica Vlll.

Rojas, D. 1989. Base de datos de Museo Nacional de Costa Rica. Documento inédito.

SheETs, P. 1984a. The proyecto prehistorico Arenal: an Introduction. Vínculos. Vol. io. Núm. I-2. Págs. I7-29.

SheETs, P. I984b. Chipped Stone artifacts from the cordillera de Tilaran. Vínculos. Vol. Io. Núm. I-2. Págs. I49-166.

SheETs, P. y B. McKee. 1995. Archaeology, Volcanism, and Remote Sensing in the Arenal Región, Costa Rica. Austin: University of Texas Press.

SheETs, P. I994a. The proyecto prehistorico Arenal: an Introduction. En: Sheets, P. y B. McKee (eds.), Archaeology, Volcanism, and Remote Sensing in the Arenal Región, Costa Rica. Págs. 73-86. Austin: University of Texas Press.

SheETs, P. 1994b. Summary and Conclusions. En: Sheets, P. y B. McKee (eds.), Archaeology, Volcanism, and Remote Sensing in the Arenal Región, Costa Rica. Págs. 312-326. Austin: University of Texas Press.

SHEETs, P. 2008. Memoria social perdurable a pesar de desastres volcánicos en el área de Arenal. Vínculos. Vol 3I. Num I-2. Págs. I-24.

SNARSKIS, M. I978. The archaeology of the Central Atlantic Watershed of Costa Rica. Disertación doctoral (Ph.D.). New York: Department of Anthropology, Columbia University.

Thomas, J. (2002). The politics of Vision and the Archaeologies of Landscape. En B. Bender (ed.): Landscape. Politics and Perspectives. Inglaterra: Berg Publishers. 
13 Alberto Venegas Ramos

La Prehistoria a través del videojuego: representaciones, tipologías y causas. The Prehistory through the Videogames: Representations, Tipologies and Causes

Roberto Martínez González \& Larissa Mendoza STRAFFON

El arte de morir: Una aproximación a las concepciones del deceso humano en el Paleolítico Superior europeo . The Art of Death: Exploring the Conception of Human Demise in the European Upper Palaeolithic

Carlos Arteaga \& Corina liesau \& Rosario garcía \& Estefanía Pérez \& Roberto Menduiña \& Jorge Vega \& CONCEPCIÓN BLASCO

The Ditched Enclosure of Camino de las Yeseras (Madrid): A Sedimentological Approach to the Study of Some Singular Structures. El yacimiento de «Camino de las Yeseras». Una aproximación sedimentológica al estudio de algunas estructuras singulares: los fosos

\section{Manuel Alejandro Castillo Poveda}

Arqueografía del sitio arqueológico Vista al Cerro (A-516 VC) (La Fortuna de San Carlos centro-Norte de Costa Rica), esbozos de un contexto funerario en la fase Arenal (500 a.C-500 d. C) · Archeographia of the Archaeological Site Vista del Cerro (A- 516 VC) (La Fortuna de San Carlos North Central Costa Rica), Sketches of a Funerary Context in the Arenal Phase (500 BC -500 d. C)

\section{Víctor Lluís Pérez Garcia}

Las interpretaciones arqueológicas y la aparición de fortificaciones en el período protohistórico de Corea (300 a.C. - 300 d.C.) . The Archaeological Interpretations and the Emergence of Fortifications in the Protohistoric Period of Korea (300 BC - 300 AD)

\section{$14.9 M^{a}$ ÁNGELES GUTIÉRREZ BEHEMERID}

La decoración escultórico-arquitectónica de carácter funerario en el Conventus Cluniensis . Funerary Type Sculptural-Architectural Decoration in the Conventus Cluniensis

199 Laura Madurga Azores

La caricaturización del simposio en una pintura nilótica: La Casa del Médico de Pompeya (VIII 5, 24) . The Caricature of the Symposium in a Nilotic Painting: The Casa del Medico of Pompeii (VIII 5, 24)

\section{Antonio Malalana Ureña \\ Maŷrit durante los siglos IX-XI. Arquitectura militar, población} y territorio - Maŷrit during the IX-XI Centuries. Military Architecture, Population and Land

249 Antonio josé Pérez Salguero

Los candiles cerámicos como indicadores de la minería medieval andalusí en Sierra de Lújar (Granada) . Ceramic Candles as Indicators of Andalusí Medieval Mining in Sierra de Lújar (Granada) 